\title{
La inspiración confesional de la ley de libertad religiosa española: laicidad de colaboración
}

The Confessional Frame of The Spanish Religious Freedom Law: Secularism and Colaboration

Marta García-Alonso

UNED

DOI: http://dx.doi.org/10.15366/bp2018.19.009

Bajo Palabra. II Época. No19. Pgs: 189-210 


\section{Resumen}

En este artículo intentamos mostrar que el modelo de laicidad español existente debería ser definido en términos de colaboración. Y ello, en base a que la libertad religiosa es interpretada jurídicamente por nuestros tribunales en términos católicos, como una mera implementación de la Declaraciones y Constituciones conciliares. La Iglesia católica ha conseguido imponer su interpretación a través del blindaje de privilegios en forma de Acuerdos.

Palabras clave: libertad religiosa, laicidad, España, ley religiosa.

\section{Abstract}

In this paper, we try to show that the existing Spanish secular model should be defined in terms of collaboration. Religious freedom is interpreted by Spanish judges in a Catholic framework, as an implementation of the Second Vatican Council's Declarations and Constitutions. In this sense, the Catholic Church has managed to impose its authority through privileged agreements with the Spanish State.

Keywords: religious freedom, secularism, Spain, religious law. 


\section{Introducción}

Según el barómetro del CIS de abril de 2015, si bien la mayoría de los españoles se declara católico (69\%), se trata de una afirmación un tanto genérica puesto que cada vez son menos los que acuden a Misa (58\%), porcentaje que se mantiene estable en 2017, con una ligera subida ${ }^{1}$. El matrimonio católico también se ha visto afectado: si hace quince años, siete de cada diez bodas se celebraban según el ritual católico, en 2013 solo tres de cada diez se celebraban según dicho culto. Para que nos hagamos una idea, en 2016 se realizaron un total de 46.436 matrimonios católicos y 122.603 civiles $^{2}$. También los bautizos han descendido, pues se ha pasado de celebrar 335.484 en 2008 a 231.254 en 2015, según datos de la propia Conferencia Episcopal ${ }^{3}$. Según esa misma fuente, los alumnos que reciben enseñanza religiosa católica en España suponen un 63 \%, mientras que en 2008 el total era del 75,7\% y durante el curso 1996-97 suponían el 80.5\%, siendo la cifra siempre superior en primaria que en secundaria ${ }^{4}$. Del mismo modo, los datos oficiales del Ministerio de Educación muestran un progresivo descenso en la demanda de la asignatura de Religión en los centros públicos españoles. Las últimas cifras con que contamos remiten al curso 2014/15, donde los alumnos que cursaron esta materia en centros públicos era el 63\% de los alumnos de Primaria, el 35.6\% en Secundaria y el 21\% de los de Bachillerato. En el curso 2003/4 el porcentaje era de 77.3\% en Primaria, $48.9 \%$ en Secundaria y $39.6 \%$ en Bachillerato 5 .

Aunque con todos estos datos a la vista podemos afirmar que estamos en una sociedad menos confesional, no hay que confundir secularización con laicidad. La secularización es un proceso sociológico e histórico que afecta de diferente manera

\footnotetext{
${ }_{1}$ Para una comparativa de los datos publicados por el CIS en abril de 2015 y 2017: http://datos.cis.es/pdf/Es3080mar_A.pdf; http://datos.cis.es/pdf/Es3173mar_A.pdf (acceso en Noviembre de 2017).

2 Pueden consultarse los datos en el Instituto Nacional de Estadística: http://www.ine.es/jaxi/Tabla.htm?path=/ t20/e301/provi/10/\&file=03009.px\&L=0 (acceso en noviembre de 2017).

${ }_{3}$ Pueden verse las memorias desde 2007 a 2015 aquí: http://www.conferenciaepiscopal.es/tema/memoria-de-actividades/ (acceso en noviembre de 2017).

${ }^{4}$ Puede consultarse la evolución anual aquí: http://www.conferenciaepiscopal.es/alumnos-que-reciben-formacion-religiosa-y-moral-catolica/ (acceso en noviembre de 2017).

5 Pueden consultarse los datos desde el curso 1996/97 al curso 2014/2015 aquí: https://www.mecd.gob.es/servicios-al-ciudadano-mecd/estadisticas/educacion/indicadores-publicaciones-sintesis/cifras-educacion-espana. html (acceso en noviembre de 2017).
} 
a las sociedades y que, en absoluto, puede decirse lineal o unidireccional, sino que es mucho más complejo. España ha entrado en un proceso en el que es menos católica pero no menos religiosa, por cuanto no solo vemos fieles de otras confesiones obtener cierto reconocimiento público de sus prácticas y creencias, sino que las estadísticas muestran que los católicos se dicen no practicantes, pero no impíos o irreligiosos. Por ejemplo, la Federación de Religiones Evangélicas de España, que agrupa más de 2.400 congregaciones, está formada por 1.200 .000 protestantes y unos 3.000 lugares de culto, y ofrece enseñanza religiosa en 500 centros escolares públicos. Según sus datos, desde el curso 2005-2006 al 2008-2009, las solicitudes de enseñanza religiosa habrían aumentado un 41\% (habrían pasado de 7.440 a 12.711). En 2011 había 9.557 alumnos y un total de 156 profesores. La razón de que haya lugares con alumnado pero sin profesorado es, según dicen, que las Comunidades Autónomas alegan falta de presupuesto para su financiación y los centros educativos, además, no tramitan la mayoría de las peticiones ${ }^{6}$. En el caso de la Unión de Comunidades Islámicas de Espańa parece que hay tan solo 55 profesores para un total de 300.000 alumnos potenciales, lo que supone un 95\% de alumnado. La demanda de religión Islámica en primaria solo está cubierta en Andalucía, Aragón, Castilla y León, Ceuta, Euskadi, Madrid y Melilla. Asimismo, el 13\% de comunidades islámicas carece de mezquita y el $95 \%$ carece de cementerio ${ }^{7}$.

Esta pluralidad religiosa de facto ha llevado a que, en los últimos años, el debate en torno a la laicidad haya pasado de tener un interés meramente académico a formar parte del debate político ${ }^{8}$. Modos diferentes de articulación que están plasmados también en los programas que los diferentes partidos políticos españoles elaboraron para las elecciones generales de 2015, por poner el ejemplo más cercano en el tiempo. El PP y Ciudadanos son partidos que se sienten cómodos con el marco actual de relaciones Iglesia/Estado. De hecho, el PP no incluía mención alguna a la laicidad, mientras que Ciudadanos proponía ciertos matices económicos, como la revisión de los privilegios económicos de la Iglesia (IBI e inmatriculaciones automáticas), o educativos, como la puesta en marcha de una asignatura no confesional de Historia de las religiones a la que se accediera mediante oposición, no por nombramiento directo del Obispo, como ocurre en la actualidad ${ }^{9}$. Para el

\footnotetext{
${ }^{6}$ http://www.actualidadevangelica.es/2011/pdf/religionyescuela2011.pdf

7 http://observatorio.hispanomuslim.es/estademograf.pdf (acceso en noviembre de 2017).

${ }^{8}$ Un análisis diferente al que hacemos aquí es el ofrecido por Beneyto, R., "El futuro de los Acuerdos entre el Estado español y la Santa Sede (según los programas de los partidos políticos a las elecciones generales del 2015)”, Revista General de Derecho Canónico y Derecho eclesiástico del Estado, 41 (2016): http://www.confer.es/789/activos/texto/6142-futuro-de-los-acuerdos-iglesia-estado--remigio-beneyto-.pdf (acceso en noviembre de 2017).

9 http://www.infolibre.es/noticias/politica/2015/10/19/albert_rivera_asegura_que_siente_comodo_con_vigente_convenio_entre_iglesia_estado_39405_1012.html (acceso en noviembre de 2017).
} 
PSOE, sin embargo, la laicidad implicaba el sometimiento de los representantes públicos al principio de neutralidad religiosa; la supresión de la referencia a la Iglesia católica en la Constitución española; la elaboración de una ley conjunta de libertad religiosa y de conciencia; la denuncia de los Acuerdos con la Santa Sede; el avance en la autofinanciación de las confesiones religiosas; la transformación de los lugares de culto públicos en lugares de oración multiconfesional; y la promoción de una escuela pública laica. Izquierda Unida es la que llevaba un programa más elaborado, seguida de Podemos: pedirán no denunciar sino anular el Concordato de 1953, los Acuerdos con la Santa Sede y sus privilegios fiscales (lo que incluye al resto de comunidades religiosas); derogar los artículos del Código Penal que tipifican como delito la ofensa a los sentimientos religiosos; y, lo más importante, pretendían cambiar la titularidad pública de las comunidades religiosas, que pasarían a someterse al derecho privado; asimismo, proponían la sustitución de la ley de libertad religiosa por una nueva ley de libertad de conciencia, con el fin de garantizar la laicidad del Estado. Izquierda Unida defenderá, además, la conversión paulatina de colegios concertados en públicos ${ }^{10}$. Estos últimos son programas ambiciosos que se apoyan en la actividad constante que en los últimos 15 años han llevado adelante asociaciones civiles como la Plataforma de Defensa del Patrimonio Navarro o Europa Laica ${ }^{11}$.

Como vemos, la laicidad española puede ser descrita, fundamentalmente, como contraria a los privilegios de una religión concreta, la católica. No obstante, en los últimos años, el debate francés en torno a la presencia de símbolos religiosos en las aulas, calles y piscinas ha influido enormemente en nuestro país ${ }^{12}$. A pesar de la poca presencia de musulmanes en España (un 4\% de la población total), el llamado burkini o el burka han sido objeto de amplia de atención mediática y se ha intentado regular su presencia en el espacio público, a imagen de las medidas impuestas en Francia ${ }^{13}$. En los últimos meses, la prohibición de la presencia de una estudiante

\footnotetext{
${ }^{10}$ Un resumen de los programas en relación a la laicidad en la web de Europa Laica: https://aicismo.org/2015/ la-laicidad-en-los-programas-electorales-de-los-partidos-para-las-generales-del-20d-2015/138111 (acceso en Noviembre de 2017).

${ }^{11}$ Europa laica: https://aicismo.org/categoria/raiz/europa_laica; Plataforma de Defensa del Patrimonio navarro: http://plataforma-ekimena.org (acceso en noviembre de 2017).

12 Un debate que, como bien señala Zazo, no implica tanto la creencia religiosa como la identidad cultural e histórica del país: Zazo E., "De cómo hemos llegado a la situación de parcialidad religiosa en (casi) todos los países europeos: Europa ante las instituciones religiosas” en Religiones en el espacio público, Romerales, E. y Zazo, E. (eds). Barcelona, Gedisa, 2016, pp. 105-133, p. 131.

13 Sin embargo, los tribunales espańoles han denegado esta solución jurídica que intentaron llevar a la práctica algunas ordenanzas municipales en Cataluña: http://www.poderjudicial.es/search/doAction?action=contentpdf\&databasematch=TS\&reference $=6650443 \&$ links $=$ prohib $\%$ C3\%ADa $\% 20 a \% 201$ as $\% 20$ musulmanas $\% 20$ uzbekas\%20usar\&optimize=20130308\&publicinterface=true (acceso en noviembre de 2017).
} 
con hyjab en la Universidad Autónoma de Madrid o la expulsión de dos usuarias de burkini en Granada, han reavivado la polémica ${ }^{14}$.

A la vista de los datos, de las propuestas de los partidos políticos y de la presencia de los debates en los medios de comunicación, podría afirmarse que el modelo de laicidad promovido por las izquierdas en España es, fundamentalmente, el republicano francés. ${ }^{15}$ No es el único, en efecto, puesto que la aceptación de la multiconfesionalidad social lleva a algunos a defender algunos elementos de laicidad positiva o de reconocimiento, con el modelo canadiense o estadounidense como referente a tener en cuenta ${ }^{16}$. La laicidad que defienden las derechas es, sin embargo, una laicidad de colaboración. Veamos primero en qué consiste el modelo español actual y cuáles son sus fundamentos para pasar, posteriormente, a explicar en qué se diferencian las alternativas propuestas en los otros dos modelos de laicidad presentes en el vocabulario político español.

\section{La ley de libertad religiosa en España}

Se ha Dicho QUe la aConfesionalidad del Estado y la Ley de Libertad Religiosa (LLR) española tienen en el artículo 16 de la Constitución su inspiración ${ }^{17}$. Y así lo dice expresamente dicha ley cuando señala que "el Estado garantiza el derecho fun-

\footnotetext{
${ }^{14}$ En 2015 se impidió a Soraya Malick, estudiante de la Facultad de Educación de Zaragoza, acudir a la Universidad con hyjab. En 2017 el conflicto tuvo lugar con una estudiante de Derecho de la Autónoma, Hana. En ambos casos, los compañeros de clase se pusieron del lado de las alumnas. En el caso del burkini, ambas usuarias cumplían los requisitos de higiene requeridos, a pesar de lo cual fueron expulsadas. Una recopilación de noticias relacionadas con el burka en España: https://laicismo.org/categoria/raiz/observatorio/observatorio-observatorio/simbolos-religiosos-y-laicismo/el-velo-y-otros-simbolos-al-vestir (acceso en noviembre de 2017). Sobre la complejidad del Islam en Europa y su sentido identitario: Zazo, E., "Cristianismo difuso e islam minoritario en las ciudades europeas" Philosophical Readings 8/3 (2016), pp. 230-237. Asimismo, Gómez García, L., "Dios es lo más. Jóvenes musulmanes e islamofobia”, Afkar ideas 50 (2016), pp. 20-22.

15 "Sánchez sobre el Estado laico: 'Mi ejemplo es la República francesa”, El País, 20 de octubre de 2015. http://politica.elpais.com/politica/2015/10/20/actualidad/1445334794_267106.html (acceso en noviembre de 2017).

${ }^{16}$ Por ejemplo, Vázquez Alonso, V., Laicidad y Constitución, Madrid, CEP, 2012. En la web de la Fundación Cives se puede leer: "Precisamente es la pluralidad ideológica y religiosa, la secularización extensa de la sociedad actual, la multiculturalidad creciente en sociedades cada día más abiertas y globalizadas, reflejada en las comunidades escolares, una de las razones más poderosas para garantizar la neutralidad y laicidad de los centros públicos de un sistema democrático": http://www.fundacioncives.org/Lineas-accion-derecho-educacion.php (acceso en noviembre 2017).

17 "1. Se garantiza la libertad ideológica, religiosa y de culto de los individuos y las comunidades sin más limitación, en sus manifestaciones, que la necesaria para el mantenimiento del orden público protegido por la Ley. 2. Nadie podrá ser obligado a declarar sobre su ideología, religión o creencias. 3. Ninguna confesión tendrá carácter estatal. Los poderes públicos tendrán en cuenta las creencias religiosas de la sociedad española y mantendrán las consiguientes relaciones de cooperación con la Iglesia Católica y las demás confesiones” (Constitución espańola, art.16).
} 
damental a la libertad religiosa y de culto, reconocida en la Constitución, de acuerdo con lo prevenido en la presente Ley Orgánica” (LLR art 1.1) ${ }^{18}$. Sin embargo, los acuerdos con la Santa Sede se firman un año antes de que de la Ley de Libertad Religiosa se apruebe, en 1980, una ley que, en principio, sirve para enmarcar el alcance y los límites de la libertad religiosa en España que afecta a toda confesión religiosa, también la católica. Y este hecho no nos parece insignificante. Sin embargo, los cuatro grandes Acuerdos son de 1979 y, por tanto, anteriores a la Ley de Libertad Religiosa de 1980. Un detalle que no carece de importancia puesto que la prioridad temporal es fundamental en derecho: prior tempore, potior iure. Ello implica que, en caso de conflicto, el derecho que prevalece es el primero en el tiempo. Un aforismo acuñado en 1298, precisamente, por Bonifacio VIII en su Liber Sextus, texto que forma parte del Corpus Iuris Canonici, usado como norma eclesial hasta 1917. Un aforismo al que los Acuerdos unen su estatuto de Tratado Internacional, lo que les permite gozar de superioridad legislativa en relación a cualquier ley ordinaria, es decir, a la legislación estatal que afecte a materias de las que se ocupan los Acuerdos ${ }^{19}$. A pesar de la paradoja temporal, esta Ley de Libertad Religiosa de 1980 supone teóricamente el marco desde el que se justifican los Acuerdos con las distintas confesiones religiosas:

El Estado, teniendo en cuenta las creencias religiosas existentes en la sociedad espańola, establecerá, en su caso, Acuerdos o Convenios de cooperación con las Iglesias, Confesiones y Comunidades religiosas inscritas en el Registro y que por su ámbito y número de creyentes hayan alcanzado notorio arraigo en España (LLR, art.7).

Concepto complejo el de notorio arraigo. No se trata de un término que se haya deslizado al azar en el texto legal sino que fue incluido para establecer los límites al reconocimiento de las distintas confesiones, pues exige que la confesión sea reconocida y practicada en España por un tiempo -que, aún sin determinar, se supone amplio-, y que sus seguidores lo sean en número suficiente que justifique su reconocimiento

\footnotetext{
${ }^{18}$ No nos detendremos en el aspecto jurídico, que ha sido convenientemente tratado por especialistas. Una pequeña muestra: Puente Egido, J., "Los acuerdos entre Espańa y la Santa Sede dentro del sistema constitucional español”, Estudios eclesiásticos 62/ 242-43 (1987), pp. 263-282; Confesiones religiosas y Estado español. Régimen jurídico, Corral C. (ed)., Madrid, BAC, 2007; Llamazares, D., "Laicidad, sistema de acuerdos y confesiones minoritarias en España", Revista catalana de dret públic 33 (2006), pp. 71-112; García Pardo, D., "La Ley Orgánica de Libertad Religiosa en la Jurisprudencia", Proyección nacional e internacional de la libertad religiosa, de la Hera, A., Martínez de Codes, R.M, Ministerio de Justicia, 2001; Oliveras Jané, N. "La evolución de la Libertad Religiosa en la Jurisprudencia del Tribunal Constitucional", Revista catalana de dret públic 33 (2006), pp. 2-24; La libertad religiosa y su regulación legal, Navarro-Vals, R., Mantecón, J., Martínez Torrón J. (coords.), Iustel, 2009. Jurisprudencia sobre el tema en la web del Ministerio de Justicia: http://www.mjusticia.gob.es/ cs/Satellite/Portal/es/areas-tematicas/libertad-religiosa/jurisprudencia-interes/derecho-fundamental-libertad (acceso noviembre 2017).

19 Sentencia 207/2013 de 5 de diciembre del Pleno del Tribunal Constitucional: https://www.boe.es/buscar/doc. php?id=BOE-A-2014-224 (acceso noviembre 2017).
} 
público (tampoco se establece claramente el número necesario). La ambigüedad, sin embargo, favorece a la religión mayoritaria que definió el término, algo reconocido en los textos de los canonistas, como Gonzalo Higuera ${ }^{20}$. Los problemas de indefinición sobre la estabilidad y permanencia temporal que conlleva el concepto llegan hasta agosto de 2015, donde el notorio arraigo ha sido redefinido para especificar los elementos concretos que puedan permitir a una confesión establecer puentes con el Estado. Actualmente, se exige que lleve tiempo inscrita en el Registro de Entidades Religiosas, que esté presente en el territorio en varias comunidades autónomas, que tenga una estructura interna y una representación adecuada a su organización ${ }^{21}$.

Según esto, los Acuerdos que se han firmado hasta ahora bajo el marco de la LLR son: cuatro Acuerdos con la Santa Sede en 1979; un acuerdo con la Federación de Entidades Religiosas Evangélicas de España (FEREDE) en 1992; un acuerdo con la FCIE (comunidades israelitas de España) también en el 92; y, en ese mismo año, otro con la Comunidad Islámica de España (CIE). Ahora bien, cumplir los requisitos de notorio arraigo no significa, sin embargo, que haya obligación por parte del Estado de suscribir acuerdos con las confesiones que cumplan este requisito. Tienen reconocido notorio arraigo pero no acuerdo, la Iglesia de Jesucristo de los Santos de los Últimos días (2003); la Iglesia de los Testigos de Jehová (2006); el Budismo (2007); y la Iglesia Ortodoxa (2010). Asimismo, en septiembre de 2014 se acordó otorgar el reconocimiento civil a sus ritos matrimoniales ${ }^{22}$.

Como vemos, ninguno de los Acuerdos con la Santa Sede es posterior a la Ley de Libertad Religiosa, de ahí que nos hayamos referido a ello como paradoja temporal. Más aún, aunque cuatro de los Acuerdos fueron aprobados después de la Constitución de 1978, otro uno de ellos fue anterior. Este primer acuerdo preconstitucional que se firma en 1976, tiene por finalidad ratificar la relación del Estado Español con la Santa Sede y poner las bases de los cuatro acuerdos de 1979. El documento, además, deroga el privilegio que el Estado tenía en el nombramiento de obispos (derecho de presentación) y ratifica la competencia jurídica eclesial en delitos de orden religioso (privilegio de fuero) ${ }^{23}$. Tal y como pide este documento de 1976,

\footnotetext{
${ }^{20}$ Higuera G., "La 'Libertas Ecclesiae' como principio fundamental” en Libertad religiosa hoy en España, Corral C. (ed.), Universidad Pontificia de Comillas, 1992, pp. 45-57, p. 54.

${ }^{21}$ Pueden verse aquí: https://www.boe.es/diario_boe/txt.php?id=BOE-A-2015-8642\&lang=eu (acceso noviembre 2017).

22 Igualmente, se reconocen efectos civiles al matrimonio celebrado en la forma religiosa prevista por las iglesias, confesiones, comunidades religiosas o federaciones de las mismas que, inscritas en el Registro de Entidades Religiosas, hayan obtenido el reconocimiento de notorio arraigo en Espańa (Proyecto de Ley de la Jurisdicción Voluntaria de 5 de septiembre de 2014: http://www.congreso.es/public_oficiales/L10/CONG/BOCG/A/BOCG-10-A-112-1.PDF).

${ }^{23}$ Instrumento de Ratificación de España al Acuerdo entre la Santa Sede y el Vaticano, 28 de julio de 1976: http:// www.boe.es/buscar/doc.php?id=BOE-A-1976-18294 (acceso noviembre 2017).
} 
el resto del Concordato será actualizado en los cuatro Acuerdos que el Estado firma con la Santa Sede en 1979: Acuerdo sobre asuntos jurídicos; Acuerdo sobre Enseñanza y Asuntos Culturales; Acuerdo sobre asistencia religiosa a las Fuerzas Armadas; y Acuerdo sobre Asuntos Económicos. Este acomodo en las relaciones iglesia y Estado no fue sencillo, sino motivo de intenso debate puesto que, mientras algunos aceptaban que la mejor fórmula era la de sustituir el Concordato, aceptando cambios que no fueran de mucho calado, otros pretendían suprimirlo de raíz, alegando que el derecho común ya cubría el ejercicio de la libertad religiosa, por lo que no se necesitaban reglamentos adicionales que pudieran derivar en privilegios confesionales ${ }^{24}$. Privilegios que, como sabemos que ocurrió en cuanto se pusieron en práctica los acuerdos, incluyen facilitar la presencia de confesiones religiosas en ámbitos públicos, tanto educativos, penitenciarios, hospitalarios como militares. Ahora bien, la Iglesia católica no ha aceptado nunca que se trate de privilegios, sino que los ha interpretado como medidas implícitamente aceptadas en el desarrollo de la Ley de Libertad Religiosa. La Ley Orgánica 7/1980 de 5 de julio de Libertad Religiosa va algo más allá de lo dispuesto en la Constitución y subraya que:

para la aplicación real y efectiva de estos derechos, los poderes públicos adoptarán las medidas necesarias para facilitar la asistencia religiosa en los establecimientos públicos, militares, hospitalarios, asistenciales, penitenciarios y otros bajo su dependencia, así como la formación religiosa en centros docentes públicos (LLR, art II, 3).

Parece un resumen de los Acuerdos con la institución católica. Ahora bien, que estas facilidades de las que habla la ley, pasen por introducir las confesiones religiosas en los espacios públicos, no es una interpretación que se siga inmediatamente de la letra de la Ley o de la Constitución, sino que implica interpretar la Ley de Libertad Religiosa a la luz de los Acuerdos con la Santa Sede ${ }^{25}$. La hipótesis que avanzamos es que esta Ley de Libertad Religiosa, igual que los Acuerdos con la Iglesia católica, encuentra su verdadero sentido cuando se inscriben en el marco teórico que ofrece la Declaración Dignitatis Humanae y la Constitución Gaudium et spes del Vaticano II, y no tanto en el marco constitucional español o en la Declaración de Derechos Humanos de 1948.

\footnotetext{
${ }^{24}$ Giménez y Martínez de Carvajal, J., "Temática general de la revisión del concordato español”, La Institución concordataria en la actualidad: trabajos de la XIII Semana de derecho canónico, Salamanca, Instituto San Raimundo de Peñafort, 1971, 467-510.

${ }^{25}$ En sentido contrario, Llamazares considera que la colaboración remite al artículo 9.2 de la Constitución, siendo de contenido general: Llamazares, D., "Revisión de la ley orgánica de libertad religiosa", Laicidad y libertades 9/1 (2009), pp. 191-250.
} 


\section{La Dignitatis Humanae y la Gaudium et Spes como marco teórico de relaciones Iglesia/Estado en España}

Es ALGO COMÚNMENTE ACEPTADO que el concepto de libertad religiosa es absolutamente fundamental para comprender las relaciones que la Iglesia católica establece con los diferentes Estados, a partir de 1965. El canonista Díaz Moreno señala que "no se exagera si se afirma que, al menos en lo que respecta a la imagen de la Iglesia en relación con el mundo en el que vive encarnada, el Concilio Vaticano II puede ser definido como el Concilio de la Libertad Religiosa" ${ }^{26}$. Ahora bien ¿¿de qué forma entiende el Magisterio eclesial esta libertad?

Durante mucho tiempo la Iglesia se negó a reconocer la Libertad religiosa como principio articulador de su doctrina pública. Si bien fue una libertad recogida desde 1948 en la Declaración de Derechos Humanos, solo será aceptada por la Iglesia a partir de $1965^{27}$. Tal cambio fue propiciado por Juan XXIII quien, en su Encíclica Pacem in Terris de 1963, proclamaba que el error en la fe o la diferencia en la verdad -o, lo que es lo mismo, no encontrarse entre los fieles de la Iglesia católica y acatar su dogmática- no debía suponer merma alguna de los derechos de la persona. Este giro dogmático aceptaba, de algún modo, la presencia constante y común del error, es decir, de otras creencias alternativas, y reconocía la debilidad de la Iglesia en su erradicación. Si en tiempos pasados se afirmaba que, con la ayuda inestimable del brazo secular, el error y la herejía debían ser suprimidos de raíz, ahora se reconocía que los derechos políticos y religiosos podían desvincularse. Una senda que a la Iglesia católica le llevó nada menos que tres siglos recorrer, pues se trata de doctrinas que ya habían sido propuestas en la época de las guerras de religión del siglo XVII ${ }^{28}$.

Siguiendo esta vía, en 1965, Pablo VI publica la Dignitatis Humanae, sobre la Libertad Religiosa, cuyo título completo es el derecho de las personas y de las comunidades a la libertad social y civil en materia religiosa ${ }^{29}$. Recordemos que aparece 17 años después de que la Declaración Universal de Derechos Humanos afirmara en

\footnotetext{
${ }^{26}$ Díaz Moreno, J. M., "La libertad religiosa. Consideraciones desde la Declaración Conciliar y la Declaración de los Derechos Humanos" en La libertad religiosa hoy en España, Corral Salvador C. (ed.) Madrid, Universidad Pontificia de Comillas, 1992, p. 17.

27 Evidentemente, ello no implica que los deberes del ciudadano no se sigan supeditando a los del creyente, en función de la relación entre verdad y justicia, como recoge el conjunto de la Encíclica: http://w2.vatican.va/ content/john-xxiii/es/encyclicals/documents/hf_j-xxiii_enc_11041963_pacem.html (acceso noviembre 2017).

${ }^{28}$ La doctrina de la tolerancia política de Bayle es solo un ejemplo: García-Alonso, M., "Creencia religiosa y conciencia errónea según Pierre Bayle”, Anuario Filosófico 48/2 (2015), pp. 35-56; ídem, "Bayle’s political doctrine: a proposal to articulate tolerance and sovereignty", History of European Ideas 43/4 (2017), pp. 331-344.

29 Los textos conciliares se encuentran en Concilio Ecuménico Vaticano II. Constituciones. Decretos. Declaraciones, Madrid, BAC, 1993. Asimismo: http://www.vatican.va/archive/hist_councils/ii_vatican_council/index_sp.htm (acceso noviembre 2017).
} 
el artículo 18 que: "Toda persona tiene derecho a la libertad de pensamiento, de conciencia y de religión; este derecho incluye la libertad de cambiar de religión o de creencia; así como la libertad de manifestar su religión o su creencia, individual o colectivamente, tanto en público como en privado, por la enseñanza, la práctica, el culto y la observancia." La versión conciliar es un tanto diferente puesto que no solo exige del Estado la inmunidad a la coacción religiosa -lo que implica el derecho de todo fiel tanto a no ser forzado a actuar contra su conciencia, como a no ser impedido a expresarla de modo confesional, como colectivo social ${ }^{30}-$, sino que añade la necesidad de que el Estado reconozca el derecho a las comunidades religiosas a regirse por sus propias normas, siempre que no atenten contra el orden público (Dignitatis Humanae 4).

Ahora bien, ese límite que implica la trasgresión del orden público se define en relación a la paz pública que siempre debe estar vinculada, según la Iglesia, a la verdadera justicia, aquella que sirve como fundamento a la moralidad pública ${ }^{31}$. Y esta verdadera justicia no es cualquier justicia, como sabemos desde San Agustín ${ }^{32}$, sino la cristiana, como señala el texto conciliar constitucional Gaudium et Spes. Sobre la Iglesia en el mundo actual:

Si por autonomía de la realidad se quiere decir que las cosas creadas y la sociedad misma gozan de propias leyes y valores, que el hombre ha de descubrir, emplear y ordenar poco a poco, es absolutamente legítima esta exigencia de autonomía. No es sólo que la reclamen imperiosamente los hombres de nuestro tiempo. Es que además responde a la voluntad del Creador. (...). Por ello, la investigación metódica en todos los campos del saber, si está realizada de una forma auténticamente científica y conforme a las normas morales, nunca será en realidad contraria a la fe, porque las realidades profanas y las de la fe tienen su origen en un mismo Dios. (...) Pero si autonomía de lo temporal quiere decir que la realidad creada es independiente de Dios y que los hombres pueden usarla sin referencia al Creador, no hay creyente alguno a quien se le oculte la falsedad envuelta en tales palabras. La criatura sin el Creador desaparece. (Gaudium et Spes 36)

Efectivamente, la Dignitatis Humanae no debería leerse al margen de la Gaudium et Spes que le da sentido. Y es que a esta defensa de la libertad religiosa como derecho individual y al deber del Estado de no promover sus propios intereses, se añade el correlativo deber del Estado de promover los medios necesarios para su desarrollo, que no es otro que favorecer la educación religiosa:

\footnotetext{
30 En esto sigue de cerca la Declaración de Derechos Humanos: (Dignitatis Humanae 2).

31 Dignitatis Humanae 7.

32 Fue Lactancio el primero en negar que los romanos conocieran la verdadera justicia a causa de su desconocimiento del verdadero Dios (Lactancio, Divinae institutiones VI, 9,7). Tras sus pasos, Agustín afirmaba que solo estaba presente la verdadera justicia allí donde se vinculaba ésta a la moral cristiana (De civitate Dei XIX, 23, 5).
} 
Cada familia, en cuanto sociedad que goza de un derecho propio y primordial, tiene derecho a ordenar libremente su vida religiosa doméstica bajo la dirección de los padres. A éstos corresponde el derecho de determinar la forma de educación religiosa que se ha de dar a sus hijos, según sus propias convicciones religiosas. Así, pues, la autoridad civil debe reconocer el derecho de los padres a elegir con verdadera libertad las escuelas u otros medios de educación, sin imponerles ni directa ni indirectamente gravámenes injustos por esta libertad de elección. Se violan, además, los derechos de los padres, si se obliga a los hijos a asistir a lecciones escolares que no corresponden a la persuasión religiosa de los padres, o si se impone un único sistema de educación del que se excluye totalmente la formación religiosa. (Dignitatis Humanae 5).

A la luz de este párrafo queda más claro, por tanto, el sentido de las medidas necesarias a las que remite el artículo II, 3 citado anteriormente de la Ley de Libertad Religiosa española que acepta la tesis de la Constitución conciliar que afirma que: "este derecho de los padres lleva consigo la creación, en los centros estatales de un auténtico espacio (académico) en los cuales aquellos alumnos, cuyos padres así lo pidan, puedan recibir una adecuada formación religiosa encuadrada dentro del plan general de formación" (Gaudium et Spes 38). Toda merma de este derecho, según la Iglesia, es una obstrucción al ejercicio de un derecho fundamental de la persona. De modo que los padres no sólo tienen que poder elegir un centro de enseñanza de acuerdo con la educación que quieren dar a sus hijos sino que, según los canonistas, debe crearse un auténtico régimen de igualdad de oportunidades para crear, administrar y dirigir centros de enseńanza religiosos, centros privados con ideario propio que, evidentemente, debe ser cofinanciado por el Estado. Y según esto, el artículo II del Acuerdo sobre Enseñanza establece la obligación del Estado de incluir la enseñanza católica en todos los centros educativos en condiciones equivalentes a las demás disciplinas fundamentales. Eso sí, sin carácter obligatorio. Asimismo, el artículo III señala que los profesores de religión serán designados por la autoridad académica, pero entre aquellos que el Obispo diocesano previamente propone. Y a todos los efectos, se le debe considerar parte del Claustro de profesores. Y no se trata de enseñanza de la religión en general sino, como dice su artículo IV La enseñanza de la doctrina católica y su pedagogía, doctrina que sólo podrá ser establecida por la jerarquía eclesiástica, como señala el artículo VI ${ }^{33}$. No está de más recordar que, junto con este derecho a enseñar su propia doctrina, la Iglesia también exige el derecho a predicar sobre cualquier materia, incluida la política:

Es de justicia que pueda la Iglesia en todo momento y en todas partes predicar la fe con auténtica libertad, enseñar su doctrina social, ejercer su misión entre los hombres sin traba

${ }_{33}$ El articulado completo del Acuerdo sobre Enseńanza puede leerse aquí: http://www.boe.es/diario_boe/txt. php?id=BOE-A-1979-29491 (acceso noviembre 2017). 
alguna y dar su juicio moral, incluso sobre materias referentes al orden político, cuando lo exijan los derechos fundamentales de la persona o la salvación de las almas, utilizando todos y solos aquellos medios que sean conformes al Evangelio y al bien de todos según la diversidad de tiempos y de situaciones (Gaudium et Spes 76).

En la elaboración de los Acuerdos, la Santa Sede tiene muy presentes sus doctrinas conciliares, como no podía ser de otro modo. Ocurre que, al ser sancionados por el Estado y aceptados como tratados internacionales, estos Acuerdos implican, como consecuencia necesaria, la promoción del ideario católico del Concilio Vaticano II en el Estado español. Ninguno de los acuerdos firmados con otras confesiones en 1992 (evangélicos, musulmanes o judíos) tienen el alcance y dimensión de los católicos. Y ello a pesar de que la Constitución condena la discriminación (trato desigual) religiosa y supone que no hay confesión privilegiada. Detengámonos, brevemente, en el Acuerdo sobre Asuntos económicos, pues es el elemento que, junto con la presencia de la religión en las aulas, genera más disenso.

\section{Acuerdo sobre Asuntos Económicos}

Como indica Alejandro Torres, el sostenimiento económico de la Iglesia Católica en España, hunde sus raíces en el siglo XIX en el contexto del proceso desamortizador del patrimonio eclesiástico ${ }^{34}$. A consecuencia de la desamortización y la abolición de los diezmos, la Iglesia Católica se ve afectada por una gravísima crisis económica cuya solución pasaría por hacer del Estado su sostén económico. Es sabido que se intentó poner fin a la dotación del culto en la Constitución de la II República, donde se indicaba que habría una extinción del presupuesto destinado al clero en un plazo máximo de dos años ${ }^{35}$. Sin embargo, tras la guerra civil se reanuda la dotación presupuestaria a favor de la Iglesia y el Concordato de 1953 consagra en su artículo XIX la dotación de culto y clero, declarándola exenta de todo impuesto ${ }^{36}$. Y en el artículo II del Acuerdo de Asuntos Económicos entre el Estado y la Santa Sede,

\footnotetext{
${ }^{34}$ Los artículos de Alejandro Torres son imprescindibles para conocer la financiación de las confesiones en España: "La asignación tributaria en España a favor de la Iglesia católica. Un estudio crítico", Revista jurídica de Navarra, 34 (2002), pp. 197-226. Puede leerse, además, su conferencia en la VII Jornada de Europa laica, en febrero de 2011: "La financiación de las religiones en el Espacio Europeo: raíces públicas de la financiación de las confesiones religiosas en una Europa laica”: https://laicismo.org/data/docs/archivo_234.pdf (acceso noviembre 2017).

35 Constitución II República, art. 26: http://www.congreso.es/docu/constituciones/1931/1931_cd.pdf (acceso noviembre 2017).

36 El Concordato en su artículo XX puede leerse aquí: http://www.vatican.va/roman_curia/secretariat_state/archivio/documents/rc_seg-st_19530827_concordato-spagna_sp.html (acceso noviembre 2017).
} 
el Estado asume el compromiso de colaborar con la Iglesia en la consecución de su adecuado sostenimiento económico. Asimismo, añade que "transcurridos tres ejercicios completos desde la firma del Acuerdo, el Estado podrá asignar a la Iglesia Católica un porcentaje del rendimiento de la imposición sobre la renta o el patrimonio neto u otra de carácter personal por el procedimiento técnicamente más adecuado."

Sin embargo, como sabemos, a pesar de estos plazos, la Iglesia católica sigue siendo subvencionada por el Estado de modo evidente. La propia Conferencia episcopal estimaba unos ingresos en 2017 de 248 millones de euros ${ }^{37}$. Cifra que aumenta considerablemente si entendemos que los lugares de culto, los colegios o edificios destinados al culto (seminarios, universidades, institutos de vida consagrada...) se benefician de la exención del pago del Impuesto de Bienes Inmuebles (IBI). Un beneficio del que también gozan las confesiones protestante ${ }^{38} \mathrm{y}$ musulmana ${ }^{39}$, aunque en diferente grado que la Iglesia católica, que añade a sus privilegios la posibilidad de inmatricular bienes no directamente dedicados al culto y hacerlos de su propiedad. La inmatriculación es un privilegio exclusivo de la Iglesia católica y depende de una ley de 1946 que, en su artículo 206, la equiparaba -en tanto entidad de Derecho público con personalidad jurídica propia- a las Administraciones públicas, de modo que los obispos podían cumplir funciones propias de los funcionarios públicos y, según esto, tenían competencias para inmatricular propiedades, sin obligación alguna de hacer constar en organismo civil alguno este acto jurídico ${ }^{40}$. Gracias a esta norma preconstitucional se han inmatriculado propiedades como casas rectorales, cementerios, huertos, almacenes, colegios... Ahora bien, los templos dedicados al culto no estaban incluidos, algo que se solventó durante el Gobierno de José María Aznar extendiendo dicho privilegio a dichos inmuebles, dando pie a la inmatriculación de ermitas, iglesias e, incluso, a la mezquita de Córdoba. El párrafo del Real Decreto dice, concretamente:

\footnotetext{
37 Sin embargo, Hacienda no controla las partidas de gasto de la Iglesia y no se sabe cuánto dinero ingresan realmente, ni su destino, como señala un artículo de prensa: "El Tribunal de Cuentas denuncia el descontrol de Hacienda sobre los privilegios fiscales de la Iglesia”, InfoLibre, 18/1/2018 https://www.infolibre.es/noticias/ economia/2018/01/18/el_tribunal_cuentas_denuncia_descontrol_absoluto_los_privilegios_fiscales_iglesia_ catolica_74218_1011.html (acceso febrero 2018). Según la Conferencia episcopal: El importe de la asignación viene determinado por el resultado de la campaña de asignación correspondiente al IRPF 2014, campaña 2015. Se ha establecido como cantidad objetivo la misma cantidad que la que se obtuvo en el ejercicio anterior, es decir, 248,5 millones de euros. http://www.conferenciaepiscopal.es/fondo-comun-interdiocesano-y-presupuestos-2017 (acceso noviembre 2017).

38 El Acuerdo con FEREDE (Federación de Entidades Religiosas Evangélicas de España), en su artículo 11.3: https://mbarral.webs.ull.es/ferede.html (acceso noviembre 2017).

39 El Acuerdo con la Comisión Islámica de España señala en su artículo 11.3: http://www.boe.es/diario_boe/txt. php?id=BOE-A-1992-24855 (acceso noviembre 2017).

${ }^{40}$ http://noticias.juridicas.com/base_datos/Privado/lh.t7.html\#a206 (acceso noviembre 2017).
} 
se suprime por inconstitucional la prohibición de inscripción de los templos destinados al culto católico, y se admite, siguiendo las legislaciones especiales sobre Patrimonio del Estado y de las entidades locales, la posibilidad de inscripción de los bienes públicos con arreglo a su legislación especial (artículo 5) ${ }^{41}$.

En virtud de esta reforma, se inmatricularon 1.087 propiedades en Navarra donde, debido a la gravedad del caso, se estableció una Plataforma de Defensa del Patrimonio Navarro ${ }^{42}$, en la que constan 117 municipios adheridos. Sus denuncias han llegado a la Unión Europea y han sido respaldadas por casi todos los grupos políticos en España.

Después de este breve recorrido por los principios y consecuencias de tan solo dos de los Acuerdos, es difícil no ver en ellos la vía expedita de la promoción del ideario católico en el Estado español, doctrina que supone el pilar esencial de las relaciones iglesia/Estado del Concilio Vaticano II. Y ello a pesar de que la Constitución condena la discriminación (trato desigual) religiosa y supone que no hay confesión privilegiada. Y ello a pesar de que el Tribunal Constitucional se refiere a Espańa como un Estado de laicidad positiva. Veamos qué se quiere decir con esto.

\section{Laicidad española}

Según varias sentencias del Tribunal Constitucional, la laicidad a la que remite el Estado es la laicidad positiva o cooperativa ${ }^{43}$, así mencionada en una sentencia sobre la inscripción de la Iglesia de la Unificación en el Registro de Entidades Religiosas, otra sobre la inhabilitación eclesiástica y despido de una profesora por vivir en concubinato y la última sobre el recurso de amparo promovido por un sacerdote secularizado, ante su despido como profesor de religión ${ }^{44}$.

\footnotetext{
41 Real Decreto 1867/1998, de 4 de septiembre, por el que se modifican determinados artículos del Reglamento Hipotecario: http://noticias.juridicas.com/base_datos/Privado/rd1867-1998.html (acceso noviembre 2017).

42 http://plataforma-ekimena.org (acceso noviembre 2017).

${ }^{43}$ La SSTC 128/2007 de 4 de junio, señala: El art. 16.3 CE recoge, por su parte, el principio de neutralidad religiosa o aconfesionalidad del Estado, si bien se trata de una neutralidad complementada con dos mandatos a los poderes públicos: tener en cuenta "las creencias religiosas de la sociedad espańola" y mantener "relaciones de cooperación con la Iglesia Católica y las demás confesiones”. Al citado precepto se ha referido el Tribunal Constitucional, afirmando que declara la neutralidad religiosa del Estado -la cual veda "cualquier tipo de confusión entre funciones religiosas y estatales- aunque en un contexto de laicidad positiva o cooperativa (SSTC 42/2001, de 15 de febrero, FJ 4; 154/2002, de 18 de julio, FJ 6)": https://www.boe.es/boe/dias/2007/07/06/ pdfs/T00004-00025.pdf (acceso noviembre 2017).

${ }^{44}$ Respectivamente, SSTC 42/2001 de 15 de febrero (FJ4). SSTC 154/2002 de 18 de julio (FJ 6). SSTC 128/2007 de 4 de junio (FJ).
} 
La laicidad positiva suele remitir al modelo canadiense y americano que implica un Estado neutral, indiferente de las opciones éticas o religiosas de sus ciudadanos, sean cuales sean. Eso significa que, si bien el Estado no puede pronunciarse sobre tales asuntos, la prohibición no se extiende a sus funcionarios, a los que se exige imparcialidad, no neutralidad. Los funcionarios (maestros, jueces, policía) deberían ser evaluados por sus actos, no por sus creencias o los símbolos externos que exhiban puesto que, según esta interpretación, un signo religioso no es por sí mismo un acto de proselitismo ${ }^{45}$. La verdadera imparcialidad, como señala un decreto del Tribunal Supremo de Canadá: "no exige que el juez no tenga ni simpatías ni opiniones. Lo que exige es que sea libre de albergar y de utilizar distintos puntos de vista manteniendo una mentalidad abierta" ${ }^{46}$. Por eso, en Canadá, al hablar sobre los símbolos religiosos en la escuela, se insiste en que la neutralidad obliga a que no se reconozca políticamente ninguna religión como religión de Estado, no a que los ciudadanos escondan en público sus filiaciones religiosas. De hecho, a mediados de los ańos 90 del siglo pasado, Quebec adoptó la resolución contraria a la francesa aceptando que las niñas usaran el pañuelo en las escuelas públicas, con el fin de evitar su marginalización y promover su socialización.

El concepto que está a la base de esta laicidad positiva o abierta es la doctrina del acomodo razonable, según la cual, más que expulsar a la religión de lo público, se acepta la importancia que tiene la dimensión espiritual del individuo y su necesidad de expresión pública ${ }^{47}$. El acomodo razonable es un procedimiento según el cual se intentan paliar las desigualdades en el reconocimiento de derechos otorgados históricamente a las comunidades religiosas y a sus fieles y parte de un principio básico: la historia no es neutral y ha favorecido a unas religiones frente a otras, según el contexto. Cuando se reconoce el derecho de un judío a descansar en sábado -lo que implica exceptuarlos de la ley común que señala el domingo como día de

\footnotetext{
45 Una aplicación de la teoría de la tolerancia de John Rawls, según la cual, es necesario decidir en cuestiones políticas de modo imparcial, lo que se consigue evitando justificar nuestras opciones en función de nuestras concepciones o creencias sobre el bien (dejar al margen juicios morales). Lo que se debe tolerar es que nuestras ideas de bien no sean lo que rija el diálogo político y escuchar a los demás para buscar puntos de convergencia entre nuestras creencias y las ajenas. Sobre la tolerancia rawlsiana: Escámez Navas, S., "El estado de la virtud. Sobre la noción de tolerancia en el liberalismo político de John Rawls”, Isegoría 31 (2004), pp. 47-78.

${ }^{46}$ Citado en Maclure J., y Taylor, Ch., Laicidad y libertad de conciencia, Madrid, Alianza, 2011, p. 108.

47 La doctrina esencial de acomodo razonable puede verse en el informe de 2008 elaborado por Bouchard G. y Taylor Ch.: Building the future. A Time for Reconciliation: https:/www.mce.gouv.qc.ca/publications/CCPARDC/ rapport-final-integral-en.pdf (acceso noviembre 2017). Un análisis en Toscano, M., "La laicidad abierta. El Rapport Bouchard-Taylor y el régimen de laicidad de Québec”, Revista Laguna 26 (2010), pp. 95-108 p. 101. En el informe se mantenía la prohibición de los símbolos religiosos a los funcionarios públicos. Actualmente, Taylor defiende lo contrario, como puede verse en su libro conjunto con Maclure. Esta postura no es compartida por Bouchard: "Bouchard déplore la volte-face de Taylor sur la laïcité", Le Devoir, 17 de febrero de 2017: http://www. ledevoir.com/societe/actualites-en-societe/491886/bouchard-et-taylor-desormais-divises (acceso noviembre 2017).
} 
descanso-, se acepta que el domingo no es un día neutral sino que ha sido impuesto en nuestras sociedades por la influencia de la tradición cristiana. Del mismo modo, cuando adaptamos normas generales alimentarias ante personas vegetarianas y aceptamos ofrecer un menú alternativo a su elección, estamos apelando al mismo derecho, aceptando que algunas normas generales puedan ser discriminatorias con las minorías. Por esa razón, Milot y Baubérot redefinen la laicidad canadiense como laicidad de reconocimiento ${ }^{48}$. Por supuesto, se habla de acomodos razonables, lo que implica que la obligación de adaptar la ley general a las minorías para evitar la discriminación no es absoluta: la petición debe ser sincera, el solicitante debe demostrar que cree que su fe le obliga a determinada conducta, y esta no tiene por qué adecuarse a la ortodoxia de su comunidad religiosa o a ningún precepto objetivo. En 2004, el Tribunal Supremo de Canadá lo expresó del siguiente modo:

La libertad religiosa garantizada por la Declaración de los derechos y libertades de la persona de Quebec (y la Carta canadiense de derechos y libertades) se entiende como libertad de entregarse a prácticas y mantener creencias que tengan un vínculo con una religión, prácticas y creencias que el interesado ejerza o manifieste sinceramente, según el caso, con el objeto de comunicarse con una entidad divina o en el marco de su fe espiritual, independientemente de la cuestión de saber si la práctica o la creencia está prescrita por un dogma religioso oficial o es conforme con la postura de los representantes religiosos. Esa interpretación es compatible con un concepto personal o subjetivo de libertad religiosa. En consecuencia, el demandante que invoca esta libertad no tiene que demostrar la existencia de una obligación, exigencia o precepto religioso objetivo. Es el carácter religioso o espiritual de un acto el que conlleva la protección, no el hecho de que su observancia sea obligatoria o se considere como tal. El Estado no está en condiciones de actuar como árbitro de dogmas religiosos y no debería convertirse en uno ${ }^{49}$.

El Estado no juzga sobre el contenido de la petición sino sobre la sinceridad de la misma. Pero añade otra condición: la petición ha de ser razonada, es decir, debe demostrar la importancia que tiene dicha petición en su vida y las razones por las que considera que ha de modificarse la ley a su favor. Dicho lo cual, los tribunales pueden denegarla aludiendo a que pone en peligro una institución concreta (educación, cuidado, servicios públicos), porque atenta contra los derechos de los demás, o que supone

\footnotetext{
${ }_{48}$ Baubérot, J. y Milot, O., Lä̈cités sans frontières, Paris, Seuil, 2011, 110 y ss. En los últimos años, ha habido movimientos de intelectuales que exigen una laicidad sin adjetivos para Quebec, sin acomodos razonables. Contra la laicidad abierta se ha escrito Déclaration des Intellectuels pour la lä̈cité. Pueden verse el texto, entre otros, aquí: http://www.laicitequebec.org/textes.php (acceso noviembre 2017). Un texto que sigue esta inspiración: Baril, D. , Lamonde Y. (eds), Pour une reconnaissance de la lä̈cité au Quebec. Enjeux philosophiques, politiques et juridiques, Canada, PUL, 2013. Una discusión sobre el debate de ambas laicidades en Canada: Garant, P., "Le combat pour la laïcité ouverte", Ethique publique 13/2 (2011): https://ethiquepublique.revues.org/864\#quotation (acceso noviembre 2017).

49 Citado en Maclure y Taylor, Laicidad y libertad de conciencia, op. cit., p. 66.
} 
un gasto excesivo o dificultades graves de funcionamiento para el lugar donde pretende ponerse en marcha. En el primer caso podrían limitarse los derechos de los padres religiosos que pretendan no educar a sus hijos en asuntos comunes como la educación sexual, la educación cívica o la ética, poniendo en peligro la virtud de la tolerancia. En el segundo caso estarían recogidos los Testigos de Jehová que niegan la trasfusión sanguínea a un hijo y ponen en peligro su vida. En último caso, podríamos incluir peticiones de comida especial en comedores públicos cuando el coste es excesivo para los medios de que dispone el colegio en cuestión.

¿En qué se parece este tipo de doctrina a la que hemos analizado al referirnos al caso español? Desde nuestro punto de vista, en nada. Cuando leemos las sentencias del Tribunal Constitucional, lo que allí se protege no es al individuo sino a la confesión religiosa, pues lo que señala el Tribunal como neutralidad es la exigencia de que el Estado no se inmiscuya en decisiones confesionales ${ }^{50}$, sean estas el nombramiento de profesores de religión o su despido. Hace ya unos años, en enero de 2007, el Tribunal Constitucional se vio inmerso en un debate sobre lo que suponen este tipo de nombramientos, a raíz del caso de la profesora de Religión, María del Carmen Galayo Macías, a quien las autoridades eclesiásticas de las Islas Canarias no renovaron el contrato por mantener una relación sentimental con un hombre que no era su marido, del que se había separado previamente. El Tribunal respaldó el despido y rechazó la petición de inconstitucionalidad promovida por el Tribunal Superior de Justicia de Canarias (TSJC), en relación al marco que permitía el despido por tales razones ${ }^{51}$. En 2015, el Tribunal Superior de Justicia de Extremadura avaló el despido de un profesor de religión por haber abandonado el sacerdocio. Luis Guridi, dirigente del sindicato que agrupa a la mayoría de los docentes de religión en pleito con el episcopado, la Federación Estatal de Profesores de Enseñanza Religiosa (Feper), reitera que los profesores de religión son mayoritariamente laicos y que su trabajo no es adoctrinar o hacer proselitismo, y señala que las sentencias de los tribunales avanzan hacia un "talibanismo católico repugnante, al mejor estilo del nacionalcatolicismo que todos creíamos trasnochado, y muy distinto al Estado confesional" ${ }^{2}$. Sin embargo, la enseñanza de doctrina cristiana es el motor del cu-

\footnotetext{
50 "Sería ciertamente incompatible, tanto con la libertad religiosa colectiva o comunitaria como con el principio de neutralidad religiosa del Estado, que un Juez o Tribunal del Poder Judicial espańol pudiera revisar, controlar o modificar la apreciación de un obispo católico o evangélico, de un rabino o de un imán acerca de lo que es o no es la recta doctrina cristiana (católica o evangélica), judía o islámica, o decidir acerca de lo que es o no es testimonio de auténtica vida cristiana, cumplimiento de la Torá o vida conforme al modelo del Profeta. Estas son materias religiosas inaccesibles para el Juez estatal" (SSTC 128/2007 de 4 de junio).

51 La sentencia: https://www.boe.es/buscar/doc.php?id=BOE-T-2007-5344 (acceso noviembre 2017).

52 Suponemos que quería decir aconfesional y que se trata de una errata. Puede leerse su opinión en http://elpais. com/diario/2007/02/24/sociedad/1172271603_850215.html (acceso noviembre 2017).
} 
rrículo que ha de enseñarse, según los Acuerdos, de modo que los profesores han de seguir la moral cristiana para ser elegidos en la misión canónica que les faculta para ejercer esa tarea. Nunca fue otra la pretensión de la Iglesia, pues queda recogido en el artículo 6 del Acuerdo sobre Educación que "a la jerarquía eclesiástica corresponde señalar los contenidos de la enseñanza y formación religiosa católica, así como proponer los libros de texto y material didáctico relativos a dicha enseñanza y formación".

Como vemos, los tribunales están "resolviendo" los conflictos que atañen a la libertad religiosa en función de los Acuerdos, lo que implica aceptar la interpretación eclesial de los despidos. Ahora bien, si los motivos para retirar la idoneidad necesaria para impartir clases de religión son confesionales, el TC lo que avala en sus decisiones son los privilegios de la curia ${ }^{53}$. No decimos que no sea legal, simplemente mostramos las consecuencias de la vigencia de los Acuerdos con la Santa Sede: no se aplican, en su caso, las normas comunes del derecho laboral ${ }^{54}$. La sentencia más reciente (SSTC 128/2007 de 4 de junio), señala:

La apreciación del Ordinario del lugar acerca de si un profesor de religión católica imparte o no recta doctrina y si da o no testimonio de vida cristiana es inmune, en su núcleo, al control de los Tribunales españoles. Pero, lejos de ser contraria a la Constitución, esa inmunidad es mera y necesaria consecuencia del derecho fundamental a la libertad religiosa y del principio de neutralidad religiosa del Estado. La libertad religiosa, además de un aspecto individual, muestra otro que cabría llamar comunitario o colectivo. En esta segunda faceta son titulares de la libertad religiosa las iglesias, confesiones y comunidades religiosas (art. 2.2 Ley Orgánica 7/1980, de 5 de julio, de libertad religiosa -LOLR-; SSTC 64/1988, de 12 de abril, FJ 2; 46/2001, de 15 de febrero, FJ 5; 128/2002, de 4 de junio, FJ 3).

\section{Conclusión}

La Constitución española no eXige subordinar la interpretación de esta colaboración a los Acuerdos pero, en términos prácticos, el Tribunal constitucional hace una interpretación de la libertad religiosa entendida en términos católicos, como una mera implementación de las Declaraciones conciliares y Constituciones conciliares, que la Iglesia católica ha conseguido imponer a través de Acuerdos privilegiados que

\footnotetext{
53 La discusión sobre la idoneidad es compleja y ha generado mucha discusión. Puede verse un resumen en "Virtualidad de la motivación religiosa en la pérdida de idoneidad”, Ius Canonucum 51 (2011), pp. 627-652 (http:// dadun.unav.edu/bitstream/10171/37190/1/201411\%20IC\%20102\%20(2011.2)\%20-10.pdf)

54 Para una revisión de la inconstitucionalidad de los Acuerdos, puede leerse el artículo, previamente citado: Llamazares D., "Revisión de la ley orgánica de libertad religiosa”, Laicidad y libertades, 9/1 (2009), pp. 191-250.
} 
vinculan al Estado cada vez que legisla sobre cuestiones religiosas. De acuerdo con esto, en Espańa los católicos pueden imponer un sistema de moral para su profesorado cuya falta de acatamiento supone la pérdida de la venia docendi y, por lo tanto, de su trabajo en la institución escolar pública. Más aún, son las confesiones religiosas las que eligen por esos mismos motivos al profesorado, que imparte curriculum religioso en aulas públicas. Eso significa privilegiar la moral religiosa, puesto que el resto del profesorado no se selecciona o se excluye por motivos confesionales, de modo que un derecho confesional es privilegiado frente a derechos fundamentales.

A nuestro modo de ver, el Tribunal Constitucional habla de laicidad positiva queriendo decir laicidad de colaboración, en nada similar a la laicidad de reconocimiento, esta última propia del modelo canadiense, como hemos visto. Ciertamente, en Europa, la cooperación y la colaboración entre el Estado y las diferentes confesiones son la regla, no la excepción ${ }^{55}$. No obstante, en dicha colaboración hay grados y, como hemos visto en este artículo, el caso español lleva esta colaboración demasiado lejos. Donde la libertad religiosa y de conciencia canadiense privilegia al individuo, la ley espańola privilegia las confesiones religiosas. La libertad de conciencia, según esto, se supedita a la libertad religiosa; la ortodoxia es privilegiada por el Estado frente a la pluralidad que, de facto, recorre las diferentes comunidades de fe. Y esto tiene sus ventajas -facilita la relación bilateral entre las instancias políticas y las iglesias- y sus desventajas - deja desprotegido al individuo, en caso de conflicto con su comunidad religiosa. Eso significa que los heterodoxos verán peligrar sus derechos, en caso de enfrentarse a la interpretación ortodoxa de sus confesiones religiosas. Si la religión no puede reducirse a la conciencia individual del fiel y encerrarse en las casas (nunca ha sido así históricamente), tampoco debería identificarse exclusivamente con su implementación pública institucional o eclesial. Articular ambas adecuadamente y, a su vez, proteger los derechos de conciencia de quienes no son religiosos y no forman parte de ninguna comunidad de este tipo, es tarea del Estado y de un adecuado marco de laicidad.

Ciertamente, no hay un único modelo de laicidad y, por esa razón, los debates en torno a cuál deba ser el que articule las relaciones entre el Estado, tanto con las diferentes confesiones religiosas como con el individuo, serán complejos y no estarán exentos de dificultades. No obstante, aunque no estemos de acuerdo en el punto de llegada, sí deberíamos estarlo en el de partida. A nuestro modo de ver, este no pasa únicamente por suspender los Acuerdos de Espańa con la Santa Sede, sino por elaborar una nueva Ley Orgánica de Libertad religiosa, desligada de sus evidentes influencias conciliares.

\footnotetext{
55 En el mismo sentido, Zazo, E., "De cómo hemos llegado a la situación de parcialidad religiosa en (casi) todos los países europeos", p. 122.
} 


\section{Referencias Bibliográficas}

Baril, D., Lamonde Y. (eds), Pour une reconnaissance de la laïcité au Quebec. Enjeux philosophiques, politiques et juridiques, Canada, PUL, 2013.

Baubérot, J. y Milot, O., Laïcités sans frontières, Paris, Seuil, 2011

Bouchard G. y Taylor Ch.: Building the future. A Time for Reconciliation: https:// www.mce.gouv.qc.ca/publications/CCPARDC/rapport-final-integral-en.pdf (

Concilio Ecuménico Vaticano II. Constituciones. Decretos. Declaraciones, Madrid, BAC, 1993

Corral C. (ed)., Confesiones religiosas y Estado español. Régimen jurídico, Madrid, BAC, 2007

Díaz Moreno, J.M., "La libertad religiosa. Consideraciones desde la Declaración Conciliar y la Declaración de los Derechos Humanos" en La libertad religiosa hoy en España, Corral Salvador C. (ed.) Madrid, Universidad Pontificia de Comillas, 1992

Escámez Navas, S., "El estado de la virtud. Sobre la noción de tolerancia en el liberalismo político de John Rawls" Isegoría 31 (2004), pp. 47-78. https://doi. org/10.3989/isegoria.2004.i31.454

Garant, P., "Le combat pour la laïcité ouverte", Ethique publique 13/2 (2011): https://ethiquepublique.revues.org/864\#quotation

García Pardo, D., "La Ley Orgánica de Libertad Religiosa en la Jurisprudencia", Proyección nacional e internacional de la libertad religiosa, de la Hera, A., Martínez de Codes, R.M; Ministerio de Justicia, 2001.

García-Alonso, M., "Creencia religiosa y conciencia errónea según Pierre Bayle", Anuario Filosófico 48/2 (2015), pp. 35-56;

- "Bayle's political doctrine: a proposal to articulate tolerance and sovereignty" History of European Ideas 43/4 (2017), pp. 331 344. https://doi.org/10.1080 /01916599.2016.1203593

Giménez y Martínez de Carvajal, J., “Temática general de la revisión del concordato español", La Institución concordataria en la actualidad: trabajos de la XIII Semana de derecho canónico, Salamanca, Instituto San Raimundo de Peñafort, 1971, 467-510.

Gómez García L., Dios es lo más. Jóvenes musulmanes e islamofobia”, Afkar ideas 50 (2016), pp. 20-22. 
Higuera G., "La 'Libertas Ecclesiae' como principio fundamental" en Libertad religiosa hoy en España, Corral C. (ed), Universidad Pontificia de Comillas, 1992, pp. 45-57,

Llamazares, D., "Laicidad, sistema de acuerdos y confesiones minoritarias en España”, Revista catalana de dret públic 33 (2006), pp. 71-112;

_ "Revisión de la ley orgánica de libertad religiosa”. Laicidad y libertades 9/1 (2009), pp. 191-250.

Maclure J., y Taylor, Ch., Laicidad y libertad de conciencia, Madrid, Alianza, 2011

Navarro-Vals, R., Mantecón, J., Martínez Torrón J. (coords.), La libertad religiosa y su regulación legal, Iustel, 2009.

Oliveras Jané, N., La Ley Orgánica de Libertad Religiosa en la Jurisprudencia, "La evolución de la Libertad Religiosa en la Jurisprudencia del Tribunal Constitucional", Revista catalana de dret públic 33 (2006), pp. 2-24;

Puente Egido, J., "Los acuerdos entre Espańa y la Santa Sede dentro del sistema constitucional español", Estudios eclesiásticos 62/ 242-43 (1987), pp. 263-282

Torres A., "La asignación tributaria en España a favor de la Iglesia católica. Un estudio crítico", Revista jurídica de Navarra, 34 (2002), pp. 197-226.

_ "La financiación de las religiones en el Espacio Europeo: raíces públicas de la financiación de las confesiones religiosas en una Europa laica" (conferencia): https://laicismo.org/data/docs/archivo_234.pdf

Vázquez Alonso, V., Laicidady Constitución, Madrid, CEP, 2012.

Zazo E., "De cómo hemos llegado a la situación de parcialidad religiosa en (casi) todos los países europeos: Europa ante las instituciones religiosas" en Religiones en el espacio público, Romerales E. y Zazo E. (eds). Barcelona, Gedisa, 2016, pp. 105-133."

- "Cristianismo difuso e islam minoritario en las ciudades europeas" Philosophical Readings 8/3 (2016), pp. 230-237.

DOI: http://dx.doi.org/10.15366/bp2018.19.009

Bajo Palabra. II Época. No19. Pgs: 189-210 